\title{
The Impact of Loading Dose on Outcome in Stroke Patients Receiving Low-Dose Tissue Plasminogen Activator Thrombolytic Therapy
}

This article was published in the following Dove Press journal:

Drug Design, Development and Therapy

\author{
Yi-Sin Wong' \\ Sheng-Feng Sung $\mathbb{( D}^{2}$ \\ Chi-Shun $\mathrm{Wu}^{2}$ \\ Yung-Chu $\mathrm{Hsu}^{2}$ \\ Yu-Hsiang $\mathrm{Su}^{2}$ \\ Ling-Chien Hung ${ }^{2}$ \\ Cheung-Ter Ong ${ }^{2}$ \\ 'Department of Family Medicine, Chia-Yi \\ Christian Hospital, Chia-Yi, Taiwan; \\ ${ }^{2}$ Department of Neurology, Chia-Y \\ Christian Hospital, Chia-Yi, Taiwan
}

Correspondence: Cheung-Ter Ong

Department of Neurology, Chia-Yi

Christian Hospital, 539 Chung-Shao Road,

Chia-Yi, Taiwan

Tel +886-5-276504l

Email ctong98@yahoo.com.tw
Background: Intravenous tissue plasminogen activator (tPA) $(0.9 \mathrm{mg} / \mathrm{kg}$, maximum $90 \mathrm{mg})$ with a bolus of $10 \%$ of the total dose given within 1-2 mins is the standard therapy for patients receiving thrombolytic therapy. Low-dose $(0.6 \mathrm{mg} / \mathrm{kg}) \mathrm{tPA}$ is also approved for thrombolytic therapy for ischemic stroke patients. Low-dose tPA is associated with a low bolus dose. It is unknown whether increasing the bolus dose in patients receiving low-dose tPA thrombolysis may improve outcomes or increase the risk of hemorrhagic transformation (HT).

Aim: This study investigated the impact of the bolus dose on the outcome in ischemic stroke patients receiving low-dose tPA thrombolytic therapy.

Methods: In this retrospective, observational study, we enrolled 214 ischemic stroke patients receiving low-dose tPA thrombolytic therapy. Of these 214 patients, 107 patients received $10 \%$ of the total dose as a bolus dose, and 107 patients received $15 \%$ of the total dose as a bolus dose. The National Institutes of Health Stroke Score (NIHSS) were evaluated before tPA infusion, $24 \mathrm{~h}$ after thrombolytic therapy, and at discharge. Stroke severity was categorized as mild (0-5), moderate (6-14), severe (15-24), or very severe $(\geq 25)$. Neurological improvement (NI) was defined as an improvement of 6 or more points in the NIHSS, and no response (NR) was defined as an increase in the NIHSS of $\leq 4$ points or a decrease $\leq 6$ points. Neurological deterioration (ND) was defined as an increase in the NIHSS $>4$ points. A good outcome was defined as a modified Ranking Score (mRS) of 0 or 1. We compared the NI, NR, and ND rates at $24 \mathrm{hrs}$ after thrombolytic therapy and discharge between the $15 \%$ and $10 \%$ bolus dose groups.

Results: In patients with mild and moderate stroke, there was no significant difference in the NI, NR, ND, and HT rates and 6-month outcomes between the $15 \%$ and $10 \%$ bolus groups. In patients with severe and very severe stroke, outcomes at 6 months were significantly better in the $15 \%$ bolus group than in the $10 \%$ bolus group. The factors affecting the outcomes of severe and very severe stroke patients are hypertension and bolus dose.

Conclusion: In severe and very severe stroke patients receiving low-dose tPA thrombolytic therapy, a bolus dose of $15 \%$ of the total dose can improve outcomes.

Keywords: ischemic stroke, tPA, thrombolysis, hypertension, outcome

\section{Introduction}

Intravenous (IV) tissue plasminogen activator (tPA) administered within $3 \mathrm{hrs}$ of stroke onset has been used to treat ischemic stroke patients since $1992 .{ }^{1}$ From then on, most studies on thrombolytic therapy for ischemic stroke patients followed the guidelines for thrombolytic therapy for acute stroke, using intravenous tPA $(0.9 \mathrm{mg} / \mathrm{kg}$, maximum $90 \mathrm{mg}$ ), with a bolus of $10 \%$ of the total dose given within $1-2 \mathrm{mins}$, followed by an 
infusion lasting 60 mins. $^{2-4}$ Owing to a higher symptomatic hemorrhagic transformation rate (sHT) in patients who received standard-dose tPA therapy, ${ }^{5-7}$ a lower dose of tPA for ischemic stroke patients was suggested. ${ }^{8,9}$ Subsequently, the Japan Alteplase Clinical Trial (J-ACT) study reported that IV low-dose tPA $(0.6 \mathrm{mg} / \mathrm{kg})$ could offer both clinical efficacy and safety as a standard dose, ${ }^{8}$ and the Japanese drug safety authority has approved the use of tPA $0.6 \mathrm{mg} / \mathrm{kg}$ for patients with ischemic stroke. Most previous studies investigating the effect of low-dose tPA were conducted according to the standard dosing guidelines, using $10 \%$ of the total dose as a loading dose of tPA. ${ }^{10-12}$ Studies reported that the efficacy and safety of low-dose tPA were comparable with that of standard-dose tPA. ${ }^{11-15}$ However, some studies reported that stroke patients receiving standard dose tPA had higher rates of favorable outcome and without significantly increased risk of symptomatic hemorrhage and mortality when compared with those of patients receiving low-dose tPA. ${ }^{16-18}$ In the Enhanced Control of Hypertension and Thrombolysis Stroke Study (ENCHANTED) study, the investigators compared the effect of low-dose $(0.6 \mathrm{mg} / \mathrm{kg})$ with standard-dose IV tPA on the outcomes in patients with ischemic stroke. The study used $15 \%$ of the total dose as a bolus dose in the low-dose tPA patient group. The authors could not confirm the superiority of a low dose to the standard dose in ischemic stroke patients. ${ }^{18}$ The thrombolytic effect of tPA lasts for only $3.5 \mathrm{hrs},{ }^{19}$ and low-dose tPA is associated with a lower bolus dose. Theoretically, a higher bolus dose may have a higher recanalization rate, and a low dose may have a lower HT rate. However, no study compared the effect of different bolus doses on the outcomes in stroke patients. Whether higher bolus dose tPA may affect the outcomes in patients receiving low-dose tPA needs further investigation. The aim of the present study is to investigate whether a $15 \%$ bolus dose is better than a $10 \%$ bolus dose in patients receiving low-dose tPA infusion.

\section{Methods}

In this retrospective, observational study, we closely followed stroke patients and performed a retrospective analysis of the data. All data were drawn from the stroke registry database of a teaching hospital in central Taiwan. Since January 2007 , we have regularly used tPA $(0.9 \mathrm{mg} / \mathrm{kg})$ for patients with acute stroke who are eligible for thrombolytic therapy. According to the guidelines for stroke management in Taiwan, a tPA dose between $0.6 \mathrm{mg} / \mathrm{Kg}$ and $0.9 \mathrm{mg} / \mathrm{kg}$ appears to be appropriate for ischemic stroke patients. ${ }^{20}$ A neurologist was consulted when patients presented to the emergency department with acute ischemic stroke within three $\mathrm{h}$ of stroke onset without contraindications to thrombolytic therapy. Based on the guidelines for stroke management in Taiwan, a low dose of tPA is feasible for thrombolytic therapy in stroke patients. From Apr 1, 2013 to Sep 15, 2016, patients in whom thrombolytic therapy was feasible and received low-dose $(0.6 \mathrm{mg} / \mathrm{kg})$ tPA were given $10 \%$ of the total dose as a bolus. From Sep 16, 2016 to Dec 31, 2017, all ischemic stroke patients in whom thrombolytic therapy was feasible received $0.6 \mathrm{mg} / \mathrm{kg} \mathrm{tPA}$ and $15 \%$ of the total dose as a bolus.

Non-contrast brain computed tomography (CT) was performed for every patient before tPA infusion. A followup CT or magnetic resonance imaging (MRI) was performed $24 \mathrm{~h}$ after tPA infusion. The National Institutes of Health Stroke Score (NIHSS) was used to assess stroke severity. An NIHSS-certified physician or nurse at our stroke center evaluated the NIHSS before tPA infusion, $24 \mathrm{~h}$ after thrombolytic therapy, and at discharge. Stroke severity was assessed according to the NIHSS before tPA infusion. Stroke severity was defined as mild stroke (0-5), moderate stroke (6-14), severe stroke (15-24), and very severe stroke $(\geq 25) .^{21}$ The patient's neurological condition was evaluated as described in our previous study. ${ }^{3}$ Early neurological improvement (ENI) was defined as a decrease of more than 6 points (compared with baseline) or an improvement in the NIHSS of 0 or 1 within $24 \mathrm{hrs}$ after tPA infusion. Neurological improvement (NI) was defined as a $>6$-point improvement (compared with baseline) or an improvement in the NIHSS of 0 or 1 at discharge. Neurological deterioration (ND) was defined as a $>4$-point increase in the NIHSS (compared with baseline) at discharge. END (early neurological deterioration) was defined as a $>4$-point increase in NIHSS (compared with baseline) within $24 \mathrm{~h}$ of tPA infusion. No response (NR) was considered as an increase in the NIHSS $\leq 4$ or a decrease in the NIHSS $\leq 6$. All brain CT and MRI scans were evaluated by a neurologist and an independent radiologist who was blind to the dose of tPA. Hemorrhagic transformation (HT) was defined as any sign of hemorrhage on follow-up CT or MRI scans. The modified Rankin Scale (mRS) was used to evaluate functional outcomes. Good and poor outcomes were defined as $m R S \leq 1$ and $m R S>1$, respectively. This study was approved by the Ethics Committee of the Chia-Yi Christian Hospital (CYCH-IRB: 096022), and written informed consent was obtained from each patient or legal representative. 


\section{Statistical Analysis}

The statistical significance of differences between bolus groups was analyzed using the chi-square or Fisher's exact test for categorical variables, the $t$-test for the time from stroke onset to tPA infusion (tPA time), and the KruskalWallis test for the NIHSS. Multiple logistic regression analysis was used to identify risk factors affecting clinical outcomes. A $P$ value $<0.05$ was considered to indicate statistical significance. The analysis was performed using SPSS software, version 21 of the SPSS system for Windows (Version 21.0. IBM Corporation. Somers, NY, USA).

\section{Results}

\section{Patient Characteristics}

From Apr 1, 2013 to Dec 31, 2017 in our hospital, 214 ischemic stroke patients received intravenous tPA $(0.6 \mathrm{mg} / \mathrm{kg})$ within $3 \mathrm{hrs}$ of stroke onset. Of these 214 patients, 107 patients (bolus 1 group) received 10\% of the total dose as a bolus, and 107 patients (bolus 2 group) received $15 \%$ of the total dose as a bolus dose within 1-2 mins and the remaining dose infusion within 60 mins. A follow-up MRI was performed in $77.6 \%$ $(166 / 214)$ of these patients, and $22.4 \%$ (48/214) of patients received a follow-up CT. Patient characteristics are presented in Table 1 . The baseline stroke severity in the 214 included patients was mild stroke in 32 , moderate stroke in 98 , severe stroke in 71 , and very severe stroke in 13 patients. In the 130 patients with mild or moderate stroke, there was no significant difference in risk factors for stroke including sex, age, hypertension, hyperlipidemia, and smoking between the $10 \%$ and $15 \%$ of total tPA dose groups (bolus 1 and 2 groups, respectively). The rate of diabetes mellitus $(0.02)$ and NIHSS $(<0.01)$ was higher in the bolus 1 group. In the 84 patients with severe or very severe stroke, there was no significant difference in the risk factors for stroke including sex, age, diabetes mellitus, hypertension, hyperlipidemia, atrial fibrillation, and smoking between the bolus 1 and bolus 2 groups. The tPA time was longer in the bolus 2 group $(p=0.02)$. All 214 patients were followed up for longer than six months.

\section{Safety and Efficacy in Mild and Moderate Stroke Patients}

Twenty-four hours after thrombolytic therapy, in the patients with mild and moderate stroke, the NI, NR, and ND rates were not significantly different between the bolus 1 and bolus 2 groups $(p=0.35)$. The NI was $33.3 \%(20 / 60)$, the NR was $63.3 \%(38 / 60)$, and the ND was $3.3 \%(2 / 60)$ in the bolus 1 group. The NI was $45.7 \%$ (32/70), the NR was $51.4 \%(36 / 70)$, and the ND was $2.8 \%(2 / 70)$ in the bolus 2 group. The NI, NR, and ND rates at discharge were also not significantly different between the bolus 1 and bolus 2 groups $(\mathrm{p}=0.44)$. The NI was $56.7 \%(34 / 60)$, the NR was $40 \%(24 / 60)$, and the ND was $3.3 \%(2 / 60)$ in the bolus 1 group. The NI was $64.2 \%(45 / 70)$, the NR was $30 \%$ $(21 / 70)$, and the ND was $5.7 \%(4 / 70)$ in the bolus 2 group. The HT rate was $3.3 \%(2 / 60)$ in the bolus 1 group and $10 \%$ $(7 / 70)$ in the bolus 2 group ( $\mathrm{p}=0.17)$, and the difference was not significant. The outcome at six months after stroke onset was not significantly different between the bolus 1 and bolus 2 groups $(p=0.09)$ : the good outcome rate was $61.7 \%(37 / 60)$ in the bolus 1 group and $75.7 \%(53 / 70)$ in the bolus 2 group.

Table I Characteristics of Patients Receiving Thrombolytic Therapy

\begin{tabular}{|c|c|c|c|c|c|c|}
\hline & \multicolumn{2}{|c|}{ Mild and Moderate Stroke $(n=130)$} & \multirow[t]{2}{*}{$\boldsymbol{P}$} & \multicolumn{2}{|c|}{ Severe and Very Severe Stroke $(n=84)$} & \multirow[t]{2}{*}{$\boldsymbol{P}$} \\
\hline & Bolus I $(n=60)$ & Bolus $2(n=70)$ & & Bolus I $(n=47)$ & Bolus $2(n=37)$ & \\
\hline $\operatorname{Sex}(M)$ & $31(51.7 \%)$ & $44(62.9 \%)$ & $0.21^{*}$ & $2 \mathrm{I}(44.7 \%)$ & $21(56.8 \%)$ & $0.37^{*}$ \\
\hline Age & $67.45 \pm 14.06$ & $65.99 \pm 13.12$ & $0.54 *$ & $71.45 \pm 13.27$ & $75.22 \pm 12.31$ & $0.18^{*}$ \\
\hline $\mathrm{DM}(\mathrm{y})$ & $26(43.3 \%)$ & $17(24.3 \%)$ & $0.02 *$ & 15 (31.9\%) & $14(37.8 \%)$ & $0.64^{*}$ \\
\hline HTN (y) & $48(80 \%)$ & $46(65.7 \%)$ & $0.07^{*}$ & $35(74.5 \%)$ & $26(70.3 \%)$ & $0.80 *$ \\
\hline Hyperlipidemia (Y) & $38(63.3 \%)$ & $36(5 \mathrm{I} .4 \%)$ & $0.21 *$ & $24(51.1 \%)$ & $19(51.4 \%)$ & $1.0 *$ \\
\hline $\operatorname{Af}(Y)$ & $14(23.3 \%)$ & $8(\mathrm{I} .4 \%)$ & $0.10 *$ & $27(57.4 \%)$ & 17 (45.9\%) & $0.38 *$ \\
\hline Smoking $(\mathrm{Y})$ & $22(36.7 \%)$ & $26(37.1 \%)$ & $1.0^{*}$ & $18(36.2 \%)$ & $12(32.4 \%)$ & $0.65^{*}$ \\
\hline NIHSS (median, IQR) & $9(7-10)$ & $6(5-7)$ & $<0.01^{\#}$ & $21(18-23)$ & $2 \mid(\mid 7-24)$ & $0.94^{\#}$ \\
\hline tPA time $(\min )$ & $118.02 \pm 45.28$ & $126.37 \pm 44.26$ & $0.27^{\$}$ & $107.47 \pm 31.8$ & $128.76 \pm 54.24$ & $0.02^{\$}$ \\
\hline
\end{tabular}

Notes: *Chi-square, ${ }^{*}$ Kruskal-Wallis, ${ }^{\$}$ T-test.

Abbreviations: DM, diabetes mellitus; HTN, hypertension; Af, atrial fibrillation; tPA, tissue plasminogen activator. 


\section{Safety and Efficacy in Severe and Very Severe Stroke Patients}

In patients with severe and very severe stroke, the NI, NR, and ND rates at $24 \mathrm{hrs}$ after thrombolytic therapy were not significantly different between the bolus 1 and bolus 2 groups $(\mathrm{p}=0.19)$. The NI was $36.1 \%(17 / 47)$, the NR was $55.3 \%$ (26/47), and the ND was $8.5 \%(4 / 47)$ in the bolus 1 group. The NI was $54.1 \%(20 / 37)$, the NR was $43.2 \%(16 / 37)$, and the ND was $2.7 \%(1 / 37)$ in the bolus 2 group. The NI, NR, and ND rates at discharge were also not significantly different between the bolus 1 and bolus 2 groups $(\mathrm{p}=0.67)$. The NI was $55.3 \%(26 / 47)$, the NR was $34 \%(16 / 47)$, and the ND was $10.6 \%(5 / 47)$ in the bolus 1 group. The NI was $64.9 \%$ (24/37), the NR was $27 \%$ (10/37), and the ND was $8.1 \%$ $(3 / 37)$ in the bolus 2 group. The HT rate was $23.4 \%(11 / 47)$ in the bolus 1 group and $27 \%(10 / 37)$ in the bolus 2 group $(\mathrm{p}=0.8)$. The 6-month outcome was better in the bolus 2 group ( $\mathrm{p}=0.004)$, and the good outcome rate was $10.6 \%$ $(5 / 47)$ in the bolus 1 group and $37.8 \%(14 / 37)$ in the bolus 2 group (Table 2).

\section{Factors Affect Outcomes of Stroke Patients}

In the univariate analysis, hypertension, atrial fibrillation, and the bolus dose affected outcomes in stroke patients, whereas sex, diabetes mellitus, hyperlipidemia, and smoking did not affect outcomes in those stroke patients (Table 3). After multiple logistic regression analysis, sex, diabetes mellitus, hypertension, hyperlipidemia, smoking, atrial fibrillation, and the bolus dose all did not affect outcomes of patients with mild and moderate stroke. However, in patients with severe and very severe stroke, hypertension was associated with a higher risk of a poor outcome $(\mathrm{p}=0.01$, odds ratio [OR]: $6.16,95 \%$ confidence interval [CI]: 1.55-24.4), and a bolus dose of $15 \%$ of the total tPA dose was associated with a lower risk of a poor outcome ( $\mathrm{p}=0.007$, OR: 0.11, 95\% CI: 0.03-0.58) (Table 4).

\section{Discussion}

Regarding the bolus dose in stroke patients receiving low-dose tPA infusion, our study has four important findings. First, the NI rate and ND rate were not significantly different between patients receiving $10 \%$ and $15 \%$ of the total tPA dose as a bolus. The patients' condition was the same at $24 \mathrm{hrs}$ after thrombolytic administration and discharge. Second, the bolus dose did not affect the HT rate. Third, hypertension increased the risk of a poor outcome in severe and very severe stroke patients (OR: 6.16, $\mathrm{p}=0.01$ ). Fourth, a higher bolus dose $(15 \%)$ can reduce the risk of a poor outcome (OR: 0.11 , $\mathrm{p}=0.007)$ in patients with severe and very severe stroke.

Previous studies investigated the effect of low-dose tPA in ischemic stroke patients and found that low-dose tPA had the same effect as the standard dose. ${ }^{11,12,14}$ Studies found that ischemic stroke patients receiving low-dose tPA thrombolytic therapy might have a lower HT rate than patients receiving the standard dose, and the effect is not inferior to that of the standard dose. ${ }^{10,22}$ However, some studies found that stroke patients receiving standard-dose tPA therapy had better outcomes than those receiving low-dose tPA therapy. ${ }^{15,16}$ All previous studies about low-dose tPA thrombolysis in ischemic stroke patients used $10 \%$ of the total dose as a bolus dose. An international study (the ENCHANTED study) compared the effect of low-dose with standard-dose intravenous alteplase on the outcomes

Table 2 The Effect of Bolus Dose on the Outcome of Thrombolytic Therapy

\begin{tabular}{|c|c|c|c|c|c|c|}
\hline & \multicolumn{2}{|c|}{ Mild and Moderate Stroke $(n=130)$} & \multirow[t]{2}{*}{$P^{*}$} & \multicolumn{2}{|c|}{ Severe and Very Severe Stroke } & \multirow[t]{2}{*}{$P^{*}$} \\
\hline & Bolus I $(n=60)$ & Bolus $2(n=70)$ & & Bolus I $(n=47)$ & Bolus $2(n=37)$ & \\
\hline $\begin{array}{l}24 \text { hr outcome } \\
\text { Improvement (NI) } \\
\text { No change (NR) } \\
\text { Deterioration (ND) }\end{array}$ & $\begin{array}{l}20(33.3 \%) \\
38(63.3 \%) \\
2(3.3 \%)\end{array}$ & $\begin{array}{l}32(45.7 \%) \\
36(51.4 \%) \\
2(2.8 \%)\end{array}$ & 0.35 & $\begin{array}{l}17(36.1 \%) \\
26(55.3 \%) \\
4(8.5 \%)\end{array}$ & $\begin{array}{l}20(54.1 \%) \\
16(43.2 \%) \\
I(2.7 \%)\end{array}$ & 0.19 \\
\hline $\begin{array}{l}\text { Discharge outcome } \\
\text { Improvement (NI) } \\
\text { No change (NR) } \\
\text { Deterioration (ND) }\end{array}$ & $\begin{array}{l}34(56.7 \%) \\
24(40 \%) \\
2(3.3 \%)\end{array}$ & $\begin{array}{l}45(64.2 \%) \\
21(30 \%) \\
4(5.7 \%)\end{array}$ & 0.44 & $\begin{array}{l}26(55.3 \%) \\
16(34.0 \%) \\
5(10.6 \%)\end{array}$ & $\begin{array}{l}24(64.9 \%) \\
10(27.0 \%) \\
3(8.1 \%)\end{array}$ & 0.67 \\
\hline Hemorrhage $(Y)$ & $2(3.3 \%)$ & $7(10 \%)$ & $0.17^{\#}$ & II (23.4\%) & $10(27.0 \%)$ & 0.80 \\
\hline 6-month good outcome & $37(61.7 \%)$ & $53(75.7 \%)$ & 0.09 & $5(10.6 \%)$ & 14 (37.8\%) & $0.004^{\#}$ \\
\hline
\end{tabular}

Notes: Bolus I: bolus with $10 \%$ of total dose, Bolus 2: bolus with 15\% of total dose, ${ }^{*}$ Chi-square test. ${ }^{\#}$ Fisher's exact test. 
Table 3 Factors Affecting the Outcome in Stroke Patients (Univariate Analysis)

\begin{tabular}{|c|c|c|c|}
\hline Character & Good Outcome & Poor Outcome & $\mathbf{P}^{*}$ \\
\hline \multicolumn{4}{|l|}{ Sex } \\
\hline Men (II7) & 65 (55.6\%) & 52 (44.4\%) & 0.17 \\
\hline Women (97) & 44 (45.4\%) & $53(54.6 \%)$ & \\
\hline \multicolumn{4}{|l|}{ Diabetes mellitus } \\
\hline Yes (72) & $30(41.7 \%)$ & $42(58.3 \%)$ & 0.06 \\
\hline No (142) & 79 (55.6\%) & 63 (44.4\%) & \\
\hline \multicolumn{4}{|l|}{ Hypertension } \\
\hline Yes (155) & 67 (43.2\%) & $88(56.8 \%)$ & $<0.01$ \\
\hline No (59) & 42 (7I.2\%) & 17 (28.8\%) & \\
\hline \multicolumn{4}{|l|}{ Hyperlipidemia } \\
\hline Yes (II7) & $53(45.3 \%)$ & $64(54.7 \%)$ & 0.07 \\
\hline No (97) & $56(57.7 \%)$ & $4 \mathrm{I}(42.3 \%)$ & \\
\hline \multicolumn{4}{|l|}{ Smoking } \\
\hline Yes (78) & $42(53.9 \%)$ & $36(46.1 \%)$ & 0.57 \\
\hline No (136) & 67 (49.3\%) & 69 (50.7\%) & \\
\hline \multicolumn{4}{|l|}{ Atrial fibrillation } \\
\hline Yes (66) & $18(27.3 \%)$ & 48 (72.7\%) & $<0.01$ \\
\hline No (148) & 91 (6I.5\%) & 57 (38.5\%) & \\
\hline \multicolumn{4}{|l|}{ Bolus } \\
\hline $10 \%(107)$ & $42(39.3 \%)$ & $65(60.7 \%)$ & 0.001 \\
\hline $15 \%(107)$ & 67 (62.6\%) & $40(37.4 \%)$ & \\
\hline
\end{tabular}

Note: *Chi-square test.

of patients with acute ischemic stroke. ${ }^{18}$ The study used $15 \%$ of the total dose as a bolus in patients receiving $0.6 \mathrm{mg} / \mathrm{kg}$ tPA therapy and used $10 \%$ of the total dose as a bolus in patients receiving a standard dose infusion. The study reported that low-dose tPA significantly decreased the sHT rate and mortality rate within seven days, whereas the mortality rate at 90 days showed no significant difference between the low dose and the standard dose. However, they found a higher risk of moderate to severe functional disability in the low-dose group than in the standard-dose group, so they could not confirm that the low-dose was not inferior to the standard-dose in ischemic stroke patients. Our study found that $50.9 \%(109 / 214)$ of patients had good outcomes (mRS 0 or 1). In agreement with the ENCHANTED study, we found a higher good outcome rate in the $15 \%$ bolus group than in the $10 \%$ bolus group [62.6\% (67/106) vs $39.3 \%(42 / 107)]$.

Our study showed HT rates of $6.92 \%(9 / 130)$ in mild and moderate stroke patients and $25 \%(21 / 84)$ in severe and very severe stroke patients. The latter was higher than the HT rate found by Mazya et $\mathrm{al}^{7}$ who reported HT rates of $11 \%$ and $10.7 \%$ in patients with severe stroke (NIHSS 15-25) and very severe stroke (NIHSS $>25$ ), respectively. This difference may be related to a higher risk of HT in the Taiwanese population. ${ }^{23}$

Our results showed that the most important factor affecting HT is stroke severity and that HT is not related to the bolus dose. This result differed from that of Mori et al, who found that no factors affected $\mathrm{sHT}^{24}$ We suspect that this difference was related to the fact that their study did not consider stroke severity.

Our study showed that hypertension was associated with poor outcomes, and a $15 \%$ bolus dose was associated with a decreased risk of poor outcomes in severe and very severe stroke patients; however, this effect was not seen in patients with mild and moderate stroke. The results suggest that the bolus dose is an important factor that affects the outcome of thrombolytic therapy in ischemic stroke patients, because a bolus dose $\left(15 \%\right.$ *body weight $\left.[\mathrm{kg}]^{*} 0.6 \mathrm{mg} / \mathrm{kg}\right)$ is the same as the bolus dose $(10 \% *$ body weight* $0.9 \mathrm{mg} / \mathrm{kg})$. Therefore, a bolus of $15 \%$ of the total dose in patients receiving low-dose $(0.6 \mathrm{mg} / \mathrm{kg}) \mathrm{tPA}$ is the same as a bolus of $10 \%$ of the total standard dose $(0.9 \mathrm{mg} / \mathrm{kg})$. Our results suggest that severe and very severe stroke patients need higher bolus doses to increase reperfusion. The ENCHANTED study was the first study to

Table 4 Factors Affecting the Outcome in Stroke Patients (Binary Logistic Regression)

\begin{tabular}{|l|l|l|l|l|l|l|}
\hline \multirow{2}{*}{ Factors } & \multicolumn{2}{l|}{ Mild and Moderate Stroke } & \multicolumn{3}{l|}{ Severe and Very Severe Stroke } \\
\cline { 2 - 7 } & $\mathbf{P}$ & OR & $\mathbf{9 5 \%} \mathbf{C l}$ & $\mathbf{P}$ & $\mathbf{O R}$ & $\mathbf{9 5 \%} \mathbf{C I}$ \\
\hline Sex & $0.8 \mathrm{I}$ & 1.14 & $0.40 \sim 3.24$ & 0.88 & 1.14 & $0.21 \sim 6.03$ \\
Diabetes mellitus & 0.30 & 1.51 & $0.66 \sim 3.65$ & 0.61 & 1.50 & $0.31 \sim 7.14$ \\
Hypertension & 0.07 & 2.67 & $0.91 \sim 7.79$ & 0.01 & 6.16 & $1.55 \sim 24.4$ \\
Hyperlipidemia & 0.12 & 1.93 & $0.83 \sim 4.52$ & 0.16 & 2.86 & $0.67 \sim 12.2$ \\
Smoking & 0.79 & 1.15 & $0.41 \sim 3.27$ & 0.75 & 0.77 & $0.15 \sim 3.97$ \\
Atrial fibrillation & 0.10 & 2.30 & $0.84 \sim 6.29$ & 0.12 & 2.94 & $0.76 \sim 11.33$ \\
Bolus 15\% & 0.48 & 0.74 & $0.32 \sim 1.70$ & 0.007 & 0.11 & $0.03 \sim 0.58$ \\
\hline
\end{tabular}

Abbreviations: $\mathrm{OR}$, odds ratio; $\mathrm{Cl}$, confidence interval. 
use a $15 \%$ bolus dose in low-dose tPA patients, and they could not confirm the non-inferiority of low-dose tPA to the standard dose. We found a $15 \%$ bolus of the total dose to be beneficial to severe and very severe stroke patients but not to mild and moderate stroke patients. It is possible that the ENCHANTED study would have reached a different conclusion if they had considered stroke severity.

The present study has several limitations. First, this was not a randomized study. We prospectively followed patients and retrospectively analyzed the data. However, our stroke registry is a detailed and accurate record of patient conditions, and our data has been cited in many studies. Second, patients who received a $10 \mathrm{mg} / \mathrm{kg}$ bolus dose were treated before those who received a $15 \%$ bolus dose. Whether this may have resulted in bias is unclear. However, in our stroke center, all patients were treated according to the same protocol except for the bolus dose. Third, this was a single-center study with a relatively small number of patients. Fourth, we did not include patients who received thrombolytic therapy more than $3 \mathrm{hrs}$ after stroke onset.

In conclusion, severe and very severe ischemic stroke patients receiving low-dose tPA thrombolytic therapy with $15 \%$ of total dose as a bolus have better outcomes and are not at an increased risk of HT compared with those receiving a $10 \%$ total dose as a bolus. A higher bolus dose (15\%) can improve outcomes and does not increase the HT risk in severe and very severe stroke patients receiving lowdose tPA thrombolytic therapy.

\section{Disclosure}

The authors report no conflicts of interest in this work.

\section{References}

1. Haley EC, Levy DE, Brott TG, et al. Urgent therapy for stroke: part II. pilot study of tissue plasminogen activator administered 91-180 minutes from onset. Stroke. 1992;23(5):641-645. doi:10.1161/01.STR.23. 5.641

2. Adams HP, Brott TG, Furlan AJ, et al. Guidelines for thrombolytic therapy for acute stroke: a supplement to the guidelines for the management of patients with acute ischemic stroke: a statement for healthcare professionals from a special writing group of the stroke council, American Heart Association. Stroke. 1996;27(9):1711-1718.

3. Ong CT, Sung SF, Wu CS, et al. Early neurological improvement after intravenous tissue plasminogen activator infusion in patients with ischemic stroke aged 80 years or older. J Chin Med Assoc. 2014;77 (4):179-183. doi:10.1016/j.jcma.2014.02.002

4. Hacke W, Kaste M, Fieschi C, et al. Randomised double-blind placebo-controlled trial of thrombolytic therapy with intravenous alteplase in acute ischaemic stroke (ECASS II). second European-Australasian acute stroke study investigators. Lancet. 1998;352(9136):1245-1251. doi:10.10 16/S0140-6736(98)08020-9
5. Chao AC, Hsu H-Y, Chung C-P, et al. Outcomes of thrombolytic therapy for acute ischemic stroke in Chinese patients: the Taiwan Thrombolytic Therapy for Acute Ischemic Stroke (TTT-AIS) study. Stroke. 2010;41(5):885-890. doi:10.1161/STROKEAHA.10 9.575605

6. Rao NM, Levine SR, Gornbein JA, Saver JL. Defining clinically relevant cerebral hemorrhage after thrombolytic therapy for stroke: analysis of the national institute of neurological disorders and stroke tissue-type plasminogen activator trials. Stroke. 2014;45 (9):2728-2733. doi:10.1161/STROKEAHA.114.005135

7. Mazya MV, Lees KR, Collas D, et al. IV thrombolysis in very severe and severe ischemic stroke: results from the SITS-ISTR registry. Neurology. 2015;85(24):2098-2106. doi:10.1212/WNL.0000000000 002199

8. Yamaguchi T, Mori E, Minematsu K, et al. Alteplase at $0.6 \mathrm{mg} / \mathrm{kg}$ for acute ischemic stroke within 3 hours of onset: Japan Alteplase Clinical Trial (J-ACT). Stroke. 2006;37(7):1810-1815. doi:10.1161/ 01.STR.0000227191.01792.e3

9. Toyoda K, Koga M, Naganuma M, et al. Routine use of intravenous low-dose recombinant tissue plasminogen activator in Japanese patients: general outcomes and prognostic factors from the SAMURAI register. Stroke. 2009;40(11):3591-3595. doi:10.1161/ STROKEAHA.109.562991

10. Miyagi T, Koga M, Shiokawa Y, et al. Intravenous alteplase at $0.6 \mathrm{mg} /$ $\mathrm{kg}$ for acute stroke patients with basilar artery occlusion: the stroke acute management with urgent risk factor assessment and improvement (SAMURAI) recombinant tissue plasminogen activator registry. J Stroke Cerebrovasc Dis. 2013;22(7):1098-1106. doi:10.1016/j. jstrokecerebrovasdis.2012.08.013

11. Chen H, Zhu G, Liu N, Zhang W. Low-dose tissue plasminogen activator is as effective as standard tissue plasminogen activator administration for the treatment of acute ischemic stroke. Curr Neurovasc Res. 2014;11(1):62-67. doi:10.2174/1567202610666131126150043

12. Kim BJ, Han M-K, Park TH, et al. Low-versus standard-dose alteplase for ischemic strokes within 4.5 hours: a comparative effectiveness and safety study. Stroke. 2015;46(9):2541-2548. doi:10.1161/ STROKEAHA.115.010180

13. Ong CT, Wong YS, Wu CS, Su YH. Outcome of stroke patients receiving different doses of recombinant tissue plasminogen activator. Drug Des Devel Ther. 2017;11:1559-1566. doi:10.2147/ DDDT.S133759

14. Liu MD, Ning WD, Wang RC, et al. Low-dose versus standard-dose tissue plasminogen activator in acute ischemic stroke in Asian populations: a meta-analysis. Medicine. 2015;94(52):e2412. doi:10.1097/ MD.0000000000002412

15. Ramaiah SS, Yan B. Low-dose tissue plasminogen activator and standard-dose tissue plasminogen activator in acute ischemic stroke in Asian populations: a review. Cerebrovasc Dis. 2013;36 (3):161-166. doi:10.1159/000354162

16. Dharmasaroja PA, Pattaraarchachai J. Low vs standard dose of recombinant tissue plasminogen activator in treating East Asian patients with acute ischemic stroke. Neurol India. 2011;59 (2):180-184. doi:10.4103/0028-3886.79132

17. Liao X, Wang Y, Pan Y, et al. Standard-dose intravenous tissue-type plasminogen activator for stroke is better than low doses. Stroke. 2014;45(8):2354-2358. doi:10.1161/STROKEAHA.114.005989

18. Anderson CS, Robinson T, Lindley RI, et al. Low-dose versus standard-dose intravenous alteplase in acute ischemic stroke. $N$ Engl J Med. 2016;374(24):2313-2323. doi:10.1056/NEJMoa1515510

19. Merino JG, Latour LLP, An LP, Hsia AW, Kang D-W, Warach S. Reperfusion half-life: a novel pharmacodynamic measure of thrombolytic activity. Stroke. 2008;39(7):2148-2150. doi:10.1161/STROKEAHA. 107.510818

20. Chang YJ, Ryu SJ, Chen JR, Hu HH, Yip PK, Chiu TF. Guidelines for the general management of patients with acute ischemic stroke. Acta Neurol Taiwan. 2008;17(4):275-294. 
21. Spartano NLP, Bernhardt JP. Prestroke physical activity to reduce stroke severity: moving to lower risk with light activity. Neurology. 2018;91(16):727-728. doi:10.1212/WNL.000000000 0006342

22. Chao AC, Liu C-K, Chen C-H, et al. Different doses of recombinant tissue-type plasminogen activator for acute stroke in Chinese patients. Stroke. 2014;45(8):2359-2365. doi:10.1161/ STROKEAHA.114.005245
23. Mehta RH, Cox M, Smith EE, et al. Race/ethnic differences in the risk of hemorrhagic complications among patients with ischemic stroke receiving thrombolytic therapy. Stroke. 2014;45(8):2263-2269. doi:10.1161/ STROKEAHA.114.005019

24. Mori E, Minematsu K, Nakagawara J, Yamaguchi T. Factors predicting outcome in stroke patients treated with $0.6 \mathrm{mg} / \mathrm{kg}$ alteplase: evidence from the Japan Alteplase Clinical Trial (J-ACT). J Stroke Cerebro. 2011;20(6):517-522.

\section{Publish your work in this journal}

Drug Design, Development and Therapy is an international, peerreviewed open-access journal that spans the spectrum of drug design and development through to clinical applications. Clinical outcomes, patient safety, and programs for the development and effective, safe, and sustained use of medicines are a feature of the journal, which has also been accepted for indexing on PubMed Central. The manuscript management system is completely online and includes a very quick and fair peer-review system, which is all easy to use. Visit http://www. dovepress.com/testimonials.php to read real quotes from published authors. 